\title{
ANALISA PENGEMBANGAN SISTEM SYNCCHROMESH UNTUK PENINGKATAN EFISIENSI PADA KENDARAAN LISTRIK
}

\author{
Emir Ridwan ${ }^{1}$, Fuad Zainuri ${ }^{2}$, Danardono S. ${ }^{3}$, M. Adhitya ${ }^{4}$, Sonki P. ${ }^{5}$, \\ Fachruddin $^{6}$, Asep Apriana ${ }^{7}$, Dianta Mustofa ${ }^{8}$, Ghany $\mathbf{H}^{9}$, Rolan $\mathrm{S}^{10}$ \\ 1,2,5,6,7,8 Jurusan Teknik Mesin , Politeknik Negeri Jakarta, \\ 2,3,4,9,10 Dept. Teknik Mesin , Fakultas Teknik, Universitas Indonesia, \\ e-mail : ${ }^{1}$ emir.ridwan@yahoo.com ;²fainuri@yahoo.co.id
}

\begin{abstract}
The transmission to be developed in this research a manual transmission type synchromesh which will be combined with the addition of replacement clutch in the form of cone. From the research of electric vehicles that have been carried out still retain the use of manual transmission for changing from conventional vehicles fuels oil by replacing the engine with a motor as a driver. This research was conducted to design synchromesh system on manual transmission which allows gearshift done without reduction of torque in one axis so as to produce gear shifting that does not experience slowing of vehicle to improve motor efficiency in electric vehicle. The mathematical model for the propulsion system is developed using the Matlab / Simulink software package, where the throttle engine angle and the power draw synchronously as a control signal to adjust the synchromesh in shifting then simulate, process and compare to obtain the effectiveness value of the control algorithm. The designs that have been made will be tested to obtain the optimal value of the transmission performance that has been designed. The simulation image of the development of the shift in the development manual transmission uses dynamic models of external and internal linkage, synchronization and drivetrain output.
\end{abstract}

Keywords: transmission , efficiency, synchromesh, simulink

\begin{abstract}
ABSTRAK
Transmisi yang akan dikembangkan pada penelitian ini adalah transmisi manual jenis synchromesh yang akan dikombinasikan dengan penambahan pengganti kopling berupa cone .Dari penelitian kendaraan listrik yang sudah dilakukan tetap mempertahankan penggunaan transmisi manual karena merubah dari kendaraan konvensional berbahan bakar minyak dengan menggantikan mesin dengan motor sebagai penggerak. Penelitian ini dilakukan untuk mendesain sistem synchromesh pada transmisi manual yang memungkinkan perpindahan gigi dilakukan tanpa pengurangan torsi di salah satu poros sehingga menghasilkan perpindahan gigi yang tidak mengalami perlambatan kendaraan untuk meningkatkan efisiensi motor pada kendaraan listrik. Model matematika untuk sistem propulsi dikembangkan dengan menggunakan paket perangkat lunak Matlab / Simulink, di mana sudut mesin throttle dan kekuatan menarik sinkron sebagai sinyal kontrol untuk mengatur synchromesh pada perilaku pergeseran, kemudian hasinya simulasi, diolah dan dibandingkan untuk mendapatkan nilai efektivitas algoritma control. Rancangan yang telah dibuat akan diuji untuk mendapatkan nilai optimal dari unjuk kerja transmisi yang telah dirancang .Gambaran simulasi pengembangan pergeseran pada transmisi manual pengembangannya menggunakan model dinamis dari eksternal dan internal linkage, sinkronisasi dan output drivetrain.
\end{abstract}

Kata kunci : transmisi, efisiensi, synchromesh, simulink

\section{PENDAHULUAN}

Sistem transmisi adalah salah satu komponen utama yang mempengaruhi daya dan konsumsi bahan bakar kendaraan. Kinerja transmisi juga berhubungan dengan efisiensi gigi, kebisingan, dan kenyamanan saat perpindahan gigi [1]. Pengembangan transmisi telah banyak dilakukan untuk memenuhi kebutuhan konsumen mulai dari model manual transmisi sampai dengan transmisi otomatis[1]. Pengembangan transmisi ini digunakan untuk kendaraan motor bakar yang 
membutuhkan bahan bakar fosil sebagai sumber tenaga mesin. Dengan melihat jumlah kendaraan yang semakin meningkat di masyarakat maka akan membutuhkan bahan bakar yang meningkat juga. Ketersediaan bahan bakar yang cenderung menurun akan menimbulkan motivasi kepada para peneliti untuk menciptakan kendaraan yang lebih ramah lingkungan seperti kendaraan dengan arus listrik sebagai sumber daya penggerak.

Secara garis besar terdapat tiga jenis transmisi kendaraan yaitu manual transmission (MT), automatic transmission (AT), dan continuous variable transmission (CVT). Manual transmission (MT) adalah paling efisien dalam konsumsi bahan bakar, sedangkan AT dan CVT lebih mudah untuk digunakan (Heath, 2007). Tingkat efisiensi MT adalah 96,2 persen, AT 86 persen, CVT 84,6 persen, dan AMT setara dengan MT (Kumbhar \& Panchagade, 2014). Keahlian pengemudi sangatlah berpengaruh dalam penggunaan manual transmisi untuk peningkatan efisiensi bahan bakar. Pada tulisan ini akan lebih banyak menyajikan manual transmisi serta perkembangannya karena transmisi ini dianggap lebih cocok digunakan untuk mobil listrik.

Manual transmisi adalah sebuah komponen yang berfungsi untuk meneruskan torsi dari mesin ke roda penggerak. Terdapat beberapa gigi didalam kotak box pada sistem transmisi yang merupakan pilihan untuk mengatur kecepatan kendaraan. Pemilihan kecepatan dilakukan oleh pengemudi secara manual dengan memanfaatkan tuas pemindah (shif lever). Terdapat beberapa tipe manual transmisi yaitu constantmesh dan synchromesh. MT synchromesh adalah transmisi yang banyak digunakan pada kendaraan. Synchronizer merupakan elemen kunci yang berfungsi untuk penyelaras putaran antar elemen sehingga dapat dilakukan perpindahan pasangan gigi dengan smooth. Beberapa sistem transmisi, seperti manual transmission (MT), Dual Clutch Transmission (DCT), dan Automatic Manual Transmission (AMT) terdapat synchronizer [1].

\section{METODE PENELITIAN}

Penelitian ini bertujuan untuk menghasilkan disain transmisi baru dengan melakukan rekayasa pada mekanisme sinkromesh sehingga lebih efisien. Adapun hal utama yang akan di rekayasa adalah geometri transmisi, konsep kerja, waktu perpindahan gigi, kualitas perpidahan gigi, dan secara otomatis akan meningkatkan efisiensi daya motor pada kendaraan listrik tersebut.Pada Gambar 1 ditampilkan Synchronizer manual transmission.

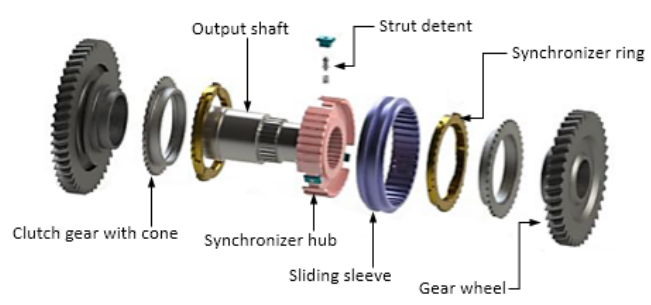

Gambar 1. Exploded view synchromesh manual transmission [1]

Berdasarkan Gambar 1 dapat dijelaskan bahwa synchronizer ring merupakan elemen penyelaras kecepatan putar antara clutch gear cone, hub, dan gear ketika sliding sleeve mulai digerakkan untuk dipasangkan. Synchronizer bekerja dengan memanfaatkan gesekan pada conus. Oleh sebab itu rekayasa synchronizer perlu dipertimbangkan untuk mengurangi dampak negative akibat gesekan. Keausan yang mungkin terjadi akan dipilih pada komponen yang lebih baik menjadi elemen yang mengalami kegagalan daripada elemen lain dalam hal ini biasanya synchronizer 
dipilih jadi elemen yang lebih lunak dari elemen sekitarnya.

Perkembangan terbaru mengenai manual transmisi adalah menciptakan kinerja manual transmisi seolah-olah otomatis yang sering disebut dengan automatic manual transmission (AMT). Secara garis besar AMT diartikan sebagai manual transmisi tanpa pedal kopling dimana pergerakan kopling diatur oleh sensor elektronik, prosesor,actuator (hidrolik atau elektromekanik), dan pergantian gigi sesuai dengan perintah pengemudi. Pada gambar 2 ditampilkan skematik AMT.

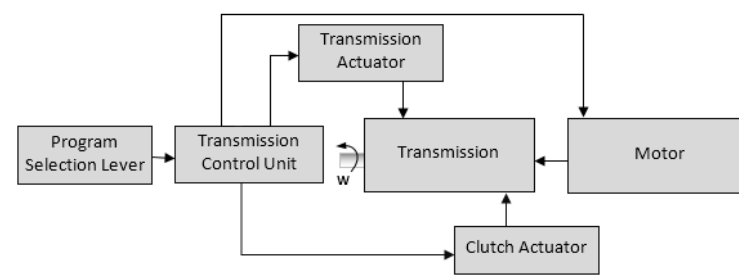

Gambar 2. Skematik AMT

Selanjutnya AMT telah dikembangkan dengan tipe transmisi zeroshift AMT. Transmisi ini adalah transmisi yang dapat melakukan perpindahan gigi tanpa membutuhkan waktu (zero second) [2]. Transmisi ini menawarkan kemudahan untuk dimanufaktur, harga yang lebih murah dari AT, penghematan bahan bakar, tidak adanya torsi yang menurun pada salah satu poros saat pergantian gigi, dan pergantian gigi yang lebih halus (seamless). Pada Gambar 3 ditampilkan zeroshift AMT [2].

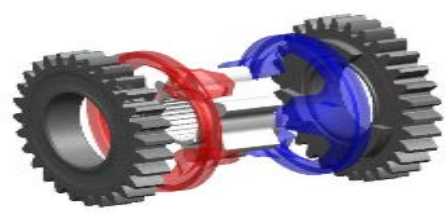

Gambar 3. Zeroshift two gear

Mekanisme zeroshift yaitu dengan mengganti komponen synchromesh pada manual transmisi dengan menggunakan zeroshift ring.
Berawal dari konsep zeroshift transmission yang memiliki keunggulan seperti fuel economy, performa, shift quality, dan mudah manufaktur maka dibuat rancangan transmisi baru untuk mobil listrik. Konsep utama adalah menghilangkan kopling pada sistem transmisi kemudian fungsi kerjanya diganti dengan cone friction dan pengaturan torsi dari motor. Kesederhanaan disain dan mekanisme kerja yang simpel adalah salah satu pertimbangan untuk memperoleh transmisi yang efektif pada mobil listrik. Berikut skematik mekanisme kerja transmisi yang dibuat seperti pada Gambar 4.

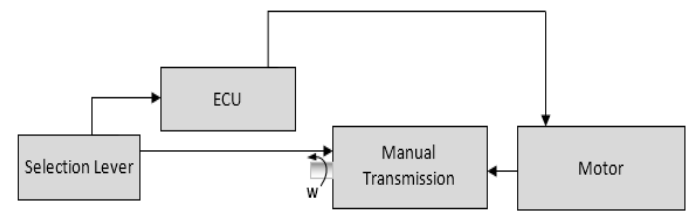

Gambar 4. Skematik manual transmission EV

Selection lever adalah tuas yang dioperasikan oleh driver untuk mengganti gigi. Ketika tuas digerakkan maka sensor akan memberikan sinyal kepada ECU lalu sinyal akan diteruskan kepada motor untuk mengatur torsi. Torsi motor yang telah menurun adalah waktu yang tepat untuk pergantian gigi. Tampilan transmisi elektrik vehicle dapat dilihat pada Gambar 5.

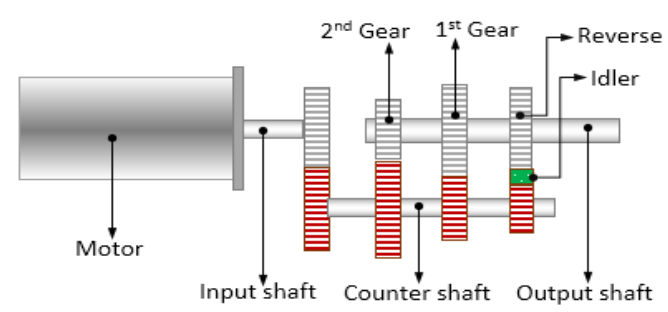

Gambar 5. Manual transmission EV

\section{HASIL dan PEMBAHASAN Hasil Rancangan}

Kopling manual transmission telah dihilangkan sehingga mekanisme kerja lebih sederhana dan lebih mudah untuk digunakan. Transmisi seperti ini akan menjadi lebih ringan apabila 
dibandingkan dengan transmisi konvensional. Rasio gigi dibuat sedemikian rupa sehingga bisa digunakan untuk kondisi jalan yang butuh traksi besar maupun untuk kecepatan tinggi.

Untuk melihat lebih detail konsep kerja transmisi ini maka dapat ditampilkan uraian elemen-elemen penyusun untuk pergantian gigi seperti pada Gambar 6 .

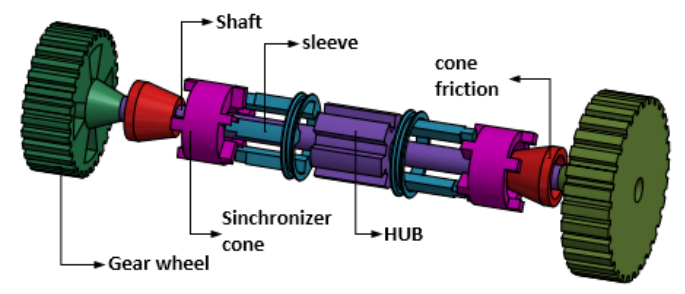

Gambar 6. Elemen penyusun synchromesh

Berdasarkan Gambar 6 dapat dijelaskan bahwa poros menyatu dengan hub sehingga penyambung utama dengan roda gigi adalah hub melalui putaran poros. Sleeve adalah elemen yang bisa digerakkan oleh operator untuk mengganti gigi. Apabila sleeve telah digeser maka synchronizer cone akan bergerak sekaligus menekan cone friction dan cone friction akan menekan cone pada roda gigi yang bertujuan untuk menyesuaikan kecepatan putar, sehingga synchronizer bisa berpasangan dengan roda gigi. Untuk lebih detail cara pergantian gigi diantara dua roda gigi terdiri dari beberapa tahap. Tahap pertama adalah sleeve digeser oleh pengemudi melalui tuas pergantian gigi sehingga sleeve tersebut mendorong synchronizer cone dan akan berputar secara bersama (Gambar 7a).

(a)

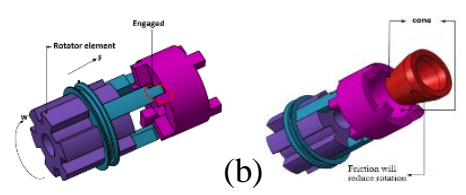

Gambar 7. Synchronizer cone with sleeve is engaged

Tahapan selanjutnya adalah penyesuaian putaran dengan cara memanfaatkan gesekan pada cone (Figure 7b). Cone yang begesekan antara elemen friction cone dengan synchronizer cone dibuat dengan beda ukuran sesuai dengan besar gesekan yang dibutuhkan. Di mana hal yang harus dipertimbangkan adalah bagaimana gesekan tersebut tidak menimbulkan masalah yang serius seperti lifetime akibat aus, temperature dan lain sebagainya. Kemudian elemen friction cone akan bergesekan dengan elemen cone gear untuk menambah pengurangan putaran antar elemen (Gambar 8a).

a)

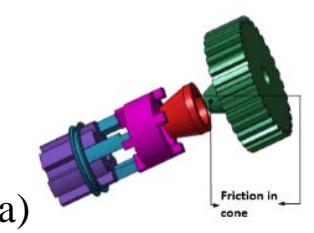

(b)

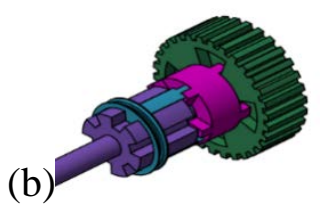

Gambar 8. Gear cone friction

Cone pada roda gigi diharapkan bukan elemen yang mudah aus karena termasuk kategori vital. Setelah pengurangan rotasi pada cone gear maka seluruh elemen akan berpasangan untuk satu tingkatan putaran gigi (Gambar 8b).

\section{Hasil perhitungan Rasio Gear Rancangan Transmisi}

Desain rasio roda gigi kendaraan dapat dilakukan dengan melakukan perhitungan torsi roda maksimum yang diperlukan untuk menggerakkan kendaraan di jalan dengan kemiringan jalan maksimum [7]. Pemuatan pada kendaraan memiliki pengaruh besar pada torsi yang dibutuhkan. Beban kendaraan adalah penumpang, bagasi, hambatan angin, dan sebagainya. Kemampuan kendaraan listrik dalam jarak tertentu menjadi hal yang penting diketahui mengingat sumber energi utama kendaraan listrik adalah baterai yang dapat diisi ulang, sehingga dengan mengetahui jarak maksimum yang dapat diambil oleh kendaraan listrik akan lebih mudah dalam menentukan posisi stasiun pengisian berada. Tabel 1 
menunjukkan spesifikasi kendaraan yang dibutuhkan.

Tabel 1. Specification of electric vehicles

\begin{tabular}{|c|l|l|}
\hline No & Item & Value \\
\hline 1 & Speed attainable & $100 \mathrm{~km} / \mathrm{h}$ \\
\hline 2 & Slope of the road & $5 \%$ \\
\hline 3 & Gross vehicle weight & $1100 \mathrm{~kg}$ \\
\hline 4 & Mileage Electric Vehicle & $400 \mathrm{~km}$ \\
\hline 5 & Wheel Radius & 0.32 \\
\hline
\end{tabular}
ditentukan berdasarkan perhitungan beban kendaraan, baik beban akibat rolling resistance, beban aerodinamik, beban akselerasi, dan beban jalan. Dari perhitungan beban diperoleh daya motor yang diperlukan untuk menggerakkan kendaraan pada kecepatan $100 \mathrm{~km} / \mathrm{jam}$ untuk $70 \mathrm{HP}$. Spesifikasi motor listrik yang dipilih untuk memenuhi kebutuhan ini adalah HPEVS AC-75 dengan kekuatan 78 HP. Properti tenaga motor dapat dilihat pada Gambar 9 [5].

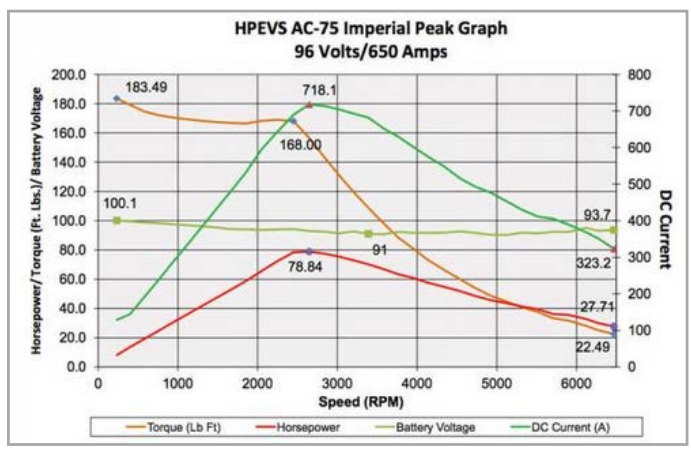

Gambar 9. Specification of electric motor with maximum power of 78.84 $H P$

Penentuan rasio gigi dapat dilakukan dengan pendekatan untuk kecepatan minimum kendaraan dan berbagai kecepatan sudut motor. Hubungan antara kecepatan sudut ke tenaga motor adalah variabel rasio gigi. Jika akselerasi yang terakumulasi sama dengan nol pada kecepatan maksimum $50 \mathrm{~m} / \mathrm{s}$ dan batas kecepatan sudut maksimum adalah 4000 RPM dan kecepatan sudut minimum adalah 1900 RPM maka rasio gigi diperoleh seperti pada Tabel 2.
Tabel 2. Gear Ratio Electric Vehicle

\begin{tabular}{|l|l|}
\hline Item & Value \\
\hline Ratio $1^{\text {st }}$ Gear G1 & 3.2 \\
\hline Ratio $2^{\text {nd }}$ Gear G2 & 1.5 \\
\hline Ratio reverse Gear GR & 2.3 \\
\hline Ratio differential & 1.7 \\
\hline
\end{tabular}

Grafik kecepatan persneling pada transmisi kendaraan listrik yang diperoleh dapat dilihat pada Gambar 10.

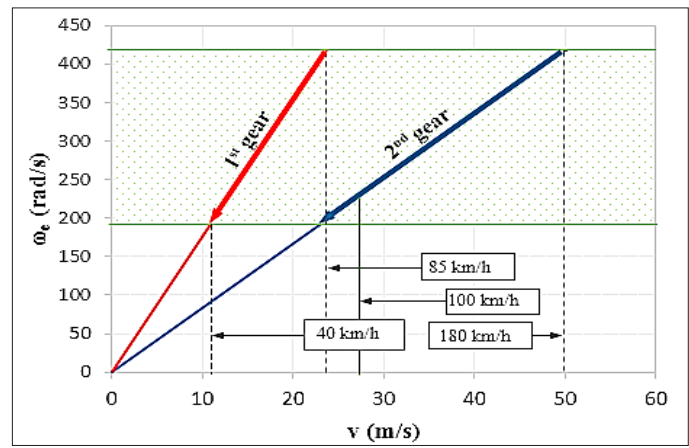

Gambar 10. The gear-speed for 2 speed transmission EV

Berdasarkan grafik pada Gambar 10 bahwa kecepatan minimum kendaraan adalah $40 \mathrm{~km} / \mathrm{jam}$ yang sedikit berbeda dari yang sebenarnya karena dalam perhitungan secara teori masih banyak idealisasi. Kecepatan kendaraan yang bisa dicapai adalah $100 \mathrm{~km} / \mathrm{jam}$ terjadi di gigi kedua. Kecepatan maksimum kendaraan dengan kondisi kritis adalah $180 \mathrm{~km} / \mathrm{jam}$ tetapi ini jarang terjadi dalam kondisi sebenarnya. Hasil desain transmisi dapat dilihat pada Gambar 11.

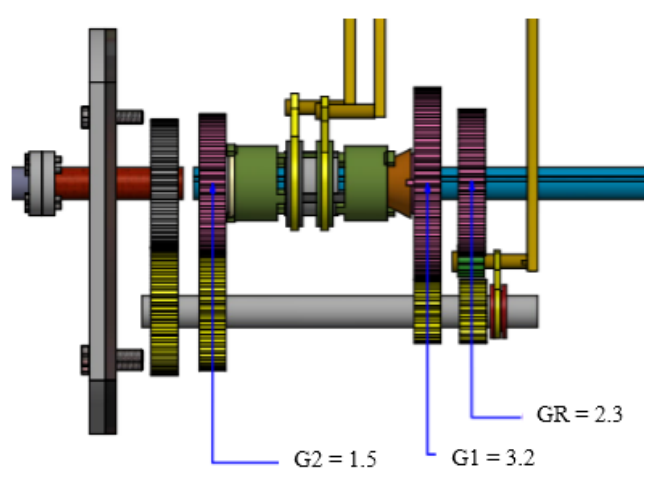

Gambar 11. EV gear transmission ratio 
Dapat disimpulkan bahwa sinkronisasi dilakukan dengan memanfaatkan beberapa gesekan, hal ini untuk mengganti fungsi kopling pada transmisi konvensional sehingga pergantian gigi dapat dilakukan dengan mulus. Sumber gaya yang bekerja adalah gaya yang diberikan oleh operator ke arah sumbu horizontal pada elemen sleeve sebesar F. Besar gaya yang bekerja pada arah normal cone friction adalah F1 sin $\Theta$. Akibat adanya gesekan pada setiap cone maka kecepatan putar akan berkurang dari elemen yang mengalami gesekan pertama sampai pada elemen lainnya. Pada Gambar 12 ditampilkan gaya yang bekerja pada system synchronizer.

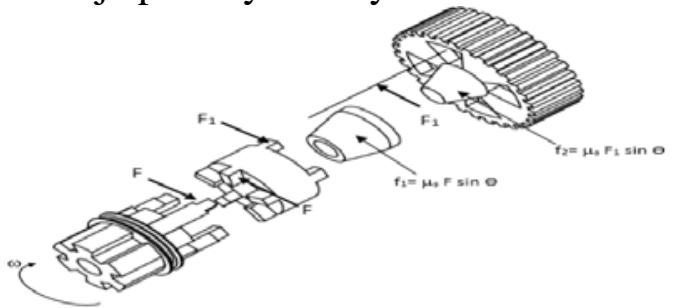

Gambar 12. Torsi dan gaya gesek

Berdasarkan Gambar 13 dapat dilihat bahwa gaya yang berasa dari sleeve adalah $\mathrm{F}$ dan akan terurai menjadi $\mathrm{F}_{2}$ sin $\Theta$ yang bekerja pada roda gigi terhadap sumbu $x$. Kecepatan putar juga mengalami hal yang sama yaitu akan terurai menjadi gesekan yang timbul. Selanjutnya torsi dan gaya gesek yang bekerja pada roda gigi dapat ditampilkan pada Gambar 13.

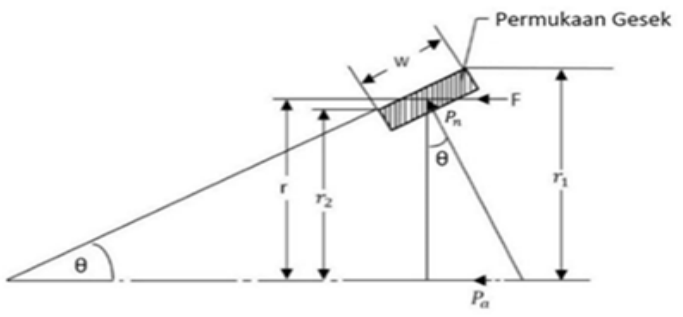

Gambar 13. Gaya yang bekerja pada synchronizer system

Apabila dilakukan perhitungan maka torsi yang bekerja pada elemen yang berpasangan antara sleeve dengan synchronizer cone adalah jarak gaya ke sumbu horizontal dikali dengan gaya yang bekerja tersebut. Kemudian torsi yang bekerja pada synchronizer cone dengan roda gigi adalah jarak gaya ke sumbu horizontal dikali dengan gaya tersebut.

\section{KESIMPULAN}

Berdasarkan hasil survei literatur dan desain telah membuat desain untuk transmisi mobil listrik telah diperoleh. Penambahan untuk mekanisme transmisi synchromesh nol menggeser topik utama sebagai pengembangan ideide baru untuk penelitian ini. Synchromesh berfungsi untuk mengurangi elemen bulat akan bermitra dengan memanfaatkan gesekan di beberapa kerucut. Mekanisme kerja transmisi manual tanpa menggunakan kopling adalah tujuan utamanya adalah memanfaatkan synchromesh dan pengaturan torsi motor sebagai pengganti clutch MT. Desain akan menjadi keuntungan tersendiri karena akan sangat efektif untuk karakter motor listrik. Jumlah perubahan gigi yang dibuat menjadi dua (2 percepatan) berguna untuk memperoleh efisiensi daya telah dipertimbangkan dari berbagai faktor. Gigi rasio satu adalah 3,2, rasio gigi dua adalah 1,5 gigi mundur rasio 2,3, dan rasio diferensial 1,7 .

Berat transmisi merupakan salah satu pertimbangan untuk meningkatkan kinerja motor listrik. Selain itu, kemudahan pembuatan, kemudahan pemasangan motor listrik, dan kemudahan penggunaan oleh pengemudi adalah hal yang perlu diperhatikan juga untuk memperoleh sistem transmisi baru yang cocok untuk kendaraan listrik. Diharapkan dari pencarian yang dilakukan pada transmisi kendaraan listrik akan membantu memecahkan masalah 
ketersediaan energi yang secara khusus mempengaruhi transportasi.

\section{UCAPAN TERIMAKASIH}

Berisi Ucapan terima kasih kepada pihak penyelenggara dana hibah penelitian dari Politeknik Negeri Jakata dan Universitas Indonesia serta Kemenristek Dikti. Seluruh pihak yang ada di Politeknik Negeri Jakarta yang telah memberikan fasilitas, motivasi, dan kesempatan untuk melaksanakan Riset ini.

\section{DAFTAR PUSTAKA}

[1] Bedmar, A. P. (2013). Synchronization processes and synchronizer mechanisms. Goteborg: Chalmers University of Technology.

[2] Cheat, R., \& Child, A. (2007). A seamless automatic manual transmission (AMT) with no torque interupt. SAE International.

[3] Heath, R. P. (2007). Seamless AMT offers efficient alternative to CVT. 20075013.
[4] Kumbhar, M. S., \& Panchagade, D. R. (2014). A Literature Review on Automated Manual Transmission (AMT). IJSRD, 1236.

[5] Evwest. (2017, April 05). Retrieved from http://www.evwest.com /catalog/product_info.php?cPath=8 \&products_id=175\&osCsid=enveq2 85s26v kelmjudp44091

[6] Fischer, R., \& Berger , R. (2010). Automation of Manual Transmissions.

[7] Jazar, R. N. (2008). Vehicle dynamic theory and application. New York: Springer.

[8] MING, C. C., \& CIN, J. S. (2010). Performance Analysis of EV Powertrain system. World Electric Vehicle Journal.

[9] Susanto N., R. Purwaningsih, and I. A. Baharullah, "Analisa Pengaruh Transmisi Mobil Manual dihadapan pengemudi pemula," J. Tek. Ind., vol. 12, no. 3, 2017. 


\section{LAMPIRAN}

Penjabaran Rumus :

$$
\begin{array}{lll}
\mathbf{p}_{\boldsymbol{u}} & =\text { tekanan normal } \\
\mathbf{r}_{1}, & =\text { jari-jari luar dan dalam } \\
\mathbf{r}_{2} & \left(\mathbf{m} / \mathbf{m}^{2}\right) \\
\boldsymbol{\Theta} & =\text { sudut gesek (sudut kontak) } \\
\boldsymbol{\mu} & =\text { koefisien gesek } \\
\mathbf{w} & =\text { lebar permukaan kontak }
\end{array}
$$

Luas permukaan kontak :

$$
\text { A } \quad=2 \pi \mathrm{r} \cdot \mathrm{w} \quad\left(\mathrm{m}^{2}\right)
$$

Gaya normal antaxa permukaan kontak

$$
\text { Fn }=\text { tekanan normal } \times \text { luas }
$$

Fn $=p_{n} \times 2 \pi \mathbf{r}$. w

Gaya aksial yang dinginkan :

$$
\mathbf{F a}=\mathbf{F n} \operatorname{Sin} \Theta
$$

Gaya gesekan atau gaya tangensial :

$$
\mathbf{F}=\mu \text {. En }
$$

Torsi gesekan :

$$
\begin{aligned}
\mathbf{T} & =\mathbf{E} \cdot \mathbf{r} \\
& =\mu \cdot \mathbf{F n} \cdot \mathbf{R} \\
& =\mu \cdot \mathbf{p}_{\mathbf{n}} \cdot 2 \pi \mathbf{r} \cdot \mathbf{w} \cdot \mathbf{r} \\
& =\mu \cdot \mathbf{p}_{\mathbf{n}} \cdot 2 \pi \mathbf{r}^{2} \cdot \mathbf{w}
\end{aligned}
$$

Power (Daya) :

$$
\begin{array}{llc}
\mathbf{P} & =\mathbf{T} \cdot \omega & (\mathrm{W}) \\
\mathbf{\Omega} & =2 \pi \mathrm{n} & \mathrm{rad} \\
\omega & \mathbf{\Omega} / 60 & \mathrm{rad} / \mathrm{s}
\end{array}
$$

Table 3. Hasil Perhitungan Gaya dan torsi

\begin{tabular}{|l|l|l|l|l|l|l|l|}
\hline $\mathrm{P}$ & $\mathrm{T}$ & $\mathrm{F}$ & $\mathrm{Fa}$ & $\mathrm{Fn}$ & \multicolumn{1}{|l|}{$\Omega$} & \multicolumn{1}{l|}{$\Omega$} & $\mathrm{n}$ \\
\hline 0,79 & 0,02 & 0,38 & 0,503 & 0,63 & 52,3 & 3142,8 & 500 \\
\hline 0,95 & 0,02 & 0,38 & 0,503 & 0,63 & 62,6 & 3771,4 & 600 \\
\hline 1,11 & 0,02 & 0,38 & 0,503 & 0,63 & 73,3 & 4400 & 700 \\
\hline 1,26 & 0,02 & 0,38 & 0,503 & 0,63 & 83,8 & 5028,5 & 800 \\
\hline 1,42 & 0,02 & 0,38 & 0,503 & 0,63 & 94,2 & 5657,1 & 900 \\
\hline 1,58 & 0,02 & 0,38 & 0,503 & 0,63 & 104,8 & 6285,7 & 1000 \\
\hline 1,74 & 0,02 & 0,38 & 0,503 & 0,63 & 115,2 & 6914,2 & 1100 \\
\hline 1,9 & 0,02 & 0,38 & 0,503 & 0,63 & 125,7 & 7542,8 & 1200 \\
\hline 2,05 & 0,02 & 0,38 & 0,503 & 0,63 & 136,2 & 8171,4 & 1300 \\
\hline 2,21 & 0,02 & 0,38 & 0,503 & 0,63 & 146,7 & 8800 & 1400 \\
\hline
\end{tabular}

